\section{EL IMPULSO EDUCATIVO, CULTURAL, CIENTÍFICO, DEPORTIVO Y SOCIOECONÓMICO QUE SIGNIFICÓ EL EXILIO ESPAÑOL REPUBLICANO EN COLOMBIA. UNA SIGNIFICATIVA APORTACIÓN AL PROGRESO}

\section{M. ${ }^{a}$ Eugenia Martínez Gorroño}

Doctora en Historia

Facultad de Formación del Profesorado y Educación Universidad Autónoma de Madrid eugenia.martinez@uam.es

Juan Luis Hernández Álvarez

Doctor en Ciencias de la Educación Facultad de Formación del Profesorado y Educación Universidad Autónoma de Madrid juanluis.hernandez@uam.es

\begin{abstract}
The Spanish group that set up the exile in Colombia, as a consequence of General Franco's coup d'état and the resultant civil war (1936-1939), has some specific characteristics that have a close relation with the receiving country needs and circumstances. In the 30s, the tension between the two principal political parties in Colombia, the concurrence and social deficiencies marked a restrictive and selective admittance. The arrival of "Spanish republicans" was quantitatively low but, because of this selection, it supposed a huge effect in society, culture, education, sport, science, industry... Now that time has passed we can analyze the Spanish exile influence on Colombia and calificate it as a "big impact", especially because the low numbers, between 500 to 700 people.
\end{abstract}

KEY WORDS: Spanish exile in Colombia in 1939; Spanish republican exiles in Colombia; History of Psychology in Colombia and Puerto Rico; History of Physical Education and Sport in Spain and Colombia.

1. LAS CIRCUNSTANCIAS SOCIALES Y POLÍTICAS de la Colombia receptora

El Partido Liberal, liderado entonces por Alfonso López Pumarejo, obtuvo la Presidencia de Colombia en 1934,

\section{THE IMPULSE THAT SUPPOSED THE SPANISH EXILE IN COLOMBIA. A SIGNIFICANT CONTRIBUTION TO PROGRESS}

RESUMEN: El grupo de españoles que conformó el exilio llegado a Colombia como consecuencia del golpe de estado del general Franco y el resultado de la Guerra Civil de 1936-1939, ofrece unas características específicas configuradas principalmente por las circunstancias y necesidades del país de acogida. En la década de los treinta, las tensiones entre los dos principales partidos colombianos, conservador y liberal, las concurrencias y las carencias sociales marcaron una acogida restrictiva y seleccionada. La llegada de "republicanos españoles" fue bastante reducida a nivel cuantitativo, y sin embargo, propiciada por dicha selección, supuso una enorme incidencia en la sociedad, la cultura, la educación, el deporte, la ciencia, la industria colombiana... La perspectiva del tiempo nos permite calificar la huella que el exilio español dejó en Colombia como de una "desmesurada incidencia" si tenemos en cuenta que su número pudo fluctuar entre las 500 y las 700 personas'.

PALABRAS CLAVE: El exilio español de 1939 en Colombia; exiliados republicanos españoles en Colombia; Historia de la Psicología en Colombia y Puerto Rico; Historia de la Educación Física y el Deporte en España y en Colombia.

tras casi 50 años en la oposición. Desde el inicio del siglo XX, este partido, en cuyo seno grupos heterogéneos representaban a sectores e intereses a menudo totalmente contrapuestos, había intentado atraer a los colectivos sociales más desfavorecidos a través de algunos de sus 
líderes populistas. Así, ante las reivindicaciones obreras y campesinas, cierta fracción del partido se propugnaba como su opción política, condicionando la formación sólida de partidos de izquierdas como alternativa al tradicional bipartidismo de liberales y conservadores.

López Pumarejo inició su mandato bajo el eslogan: "La revolución en marcha", que resumía el impulso drástico y modernizador que pretendía iniciar para promover la industrialización y el consumo. Contaba para ello con una facción liberal que generalmente respondía a una clase empresarial de la alta burguesa criolla que venía configurándose desde el siglo XIX. Se trataba de un sector con un alto nivel cultural, excepcional en el país, obtenido frecuentemente fuera de las fronteras colombianas, y que le convertía en una elite económica y cultural. En los años treinta constituía un grupo social afianzado, cuyo poder fáctico derivaba de su capacidad económica y de la propiedad de medios de difusión. Su empuje le permitió asumir la dirección del Estado, cambiar ciertas obsoletas estructuras administrativas y atenuar los poderes retrógrados de inspiración religiosa que impedían su propio progreso como grupo social y su escalada económica.

Para el desarrollo de sus proyectos, este sector necesitaba de una elite técnica y una mano de obra eficaz que no podía suministrar una población analfabeta. La industria, el comercio, la banca precisaban de una clase obrera con una mínima formación. Ni siquiera la renovación agrícola era factible con peones y encargados incapaces de leer unas instrucciones escritas y hacer cálculos elementales. Así pues, el bajo nivel cultural constituía un freno a las reformas. En 1930:

"La tasa de analfabetismo llegaba al $63 \%$ de la población en edad escolar, las escuelas normales eran muy escasas y bajo el nivel de preparación del magisterio. Los planes de estudio y los métodos de enseñanza eran anticuados y rutinarios, tanto en la escuela elemental como en la enseñanza secundaria y en la universidad. La escuela rural cubría solamente sectores mínimos de la población campesina. La inspección escolar apenas si existía y el sistema educativo en general estaba prácticamente a cargo de las instituciones religiosas" (Jaramillo Uribe, 1989, 87).

No obstante, la necesidad de elevar el nivel cultural del país no constituia el único reto para el nuevo gobierno.
Los violentos enfrentamientos por rencillas políticas, sobre todo después del triunfo liberal, y las mejores perspectivas del entorno urbano, impulsaban en la década de los treinta el abandono rural. Las oleadas migratorias modificaban la proporción entre población campesina y urbana, forzando un proceso acelerado de urbanización, principalmente de Bogotá y las grandes capitales, que originaba nuevos problemas y nuevos retos. Unos y otros, elevar la cultura y formación de los ciudadanos y atender a las nuevas necesidades creadas por la migración interna, constituyeron importantes motivos que influyeron en la predisposición para acoger exiliados que contribuyeran a solucionarlos.

En este contexto, las mujeres y hombres de ciencia y cultura movilizados por las circunstancias de la Guerra Civil española y la Segunda Guerra Mundial fueron vistos por el sector liberal como un potencial para sus intereses. Eduardo Santos, Presidente entre 1938 y 1942, que había residido en España como Embajador y periodista y era simpatizante de la Segunda República española, representaba especialmente esta idea y la difundió en el diario de su propiedad, El Tiempo de Bogotá.

Dario Echandia ${ }^{2}$ sintetizaba en las siguientes palabras la postura de aquel sector liberal, grupo con trayectoria personal y educativa cercana a la realidad europea:

"El paso revolucionario que nosotros podríamos dar hacia la creación de una vida más alta sería la importación de millares y millares de hombres que, sabiendo un oficio, se quedaran sin oficio en Europa después de la guerra. Las Leyes de inmigración se pondrán entonces en vigencia en Colombia y así se formará una sociedad mejor, después del paso de una generación" (Arizmendi Posada, 1989, 242).

La cita refleja, por un lado, el potencial que para los liberales suponían los exiliados, y, por otro, los recelos y la tradicional política restrictiva inmigratoria colombiana. Así, los liberales se debatieron en una contradicción entre, el temor de que la acogida de los "rojos" españoles supusiera la importación de ideologias "izquierdistas" socialmente perturbadoras y el servicio que podrian prestar al país. Todo ello contribuyó a una recepción selectiva.

Esta prevención liberal, agudizada por el hostigamiento del influyente sector eclesiástico, se mutaba en radical oposición entre los conservadores que propagaban augu- 
rios atemorizantes y afianzaban el tradicional paralelismo entre inmigración e introducción de ideologías "radicales" desestabilizadoras. La prensa conservadora, principalmente El Siglo de Bogotá, emprendió una campaña política contra la acogida de los "rojos españoles".

Durante el gobierno de López Pumarejo (1934-1938), Ilegaron los primeros desplazados políticos por la Guerra Civil española. Generalmente fueron vascos, que tras la toma de Bilbao por las tropas sublevadas dispusieron precozmente su salida de España. Acogidos por su elevada cualificación, casi inmediatamente les fueron adjudicados puestos de responsabilidad en instituciones estatales. Podemos citar especialmente a Andrés Perea Gallaga o a Francisco de Abrisqueta. El primero gran experto en temas fiscales y económicos como colaborador del Gobierno Autónomo Vasco. El segundo, joven economista universitario, fue vinculado inmediatamente a la Contraloría General de la República Colombiana, equivalente a los Ministerios de Hacienda europeos. Sucintamente apuntaremos que en 1947 el gobierno colombiano les otorgó a ambos la Cruz de Boyacá (Martínez Gorroño, 1996), como consecuencia del trascendente y decisivo beneficio de su labor.

Estos primeros españoles se convirtieron en un doble y relevante punto de referencia para el exilio que llegó posteriormente. Por un lado, sirvieron de vínculo con un país apartado de la problemática europea para parientes y amigos españoles desplazados por la contienda. Por otro, fueron un sólido referente para los políticos liberales. Con ellos experimentaron la posibilidad de solventar sus necesidades con la llegada de exiliados de similar cualificación profesional, cultural y científica que compartian el mismo idioma, y que estaban limitados en sus posibles actuaciones políticas a causa de su estatus de refugiados. Así hemos documentado, un número significativo de acogidos invitados personalmente por el Presidente Santos (Martínez Gorroño, 2008).

Con frecuencia, los exiliados ya instalados solicitaron al Presidente 0 a sus ministros la acogida de familiares y amigos, cuando ya se encontraban en delicadas circunstancias en Francia. En la acogida selectiva y minuciosa hemos de citar especialmente al Ministro de Relaciones Exteriores del gobierno de Santos, Luis López de Mesa, quien personificó singularmente los temores ya expuestos, exigiendo a los exiliados mediadores un compromiso de aval y garantía de la condición y cualificación de los admitidos. Aquel proceso de lenta concesión de visados favoreció la ubicación de los españoles republicanos en otros países, sobre todo cuando la presión previa a la Segunda Guerra Mundial hacía desesperada su situación en territorio francés.

Los españoles acogidos realizaron una ingente labor en torno a la cual se organizaron y estructuraron numerosos sectores colombianos. Se crearon diversas instituciones iniciadas y dirigidas por exiliados especialistas, que actuaron como motor de innovaciones y cambios que luego fueron seguidos por sus discípulos colombianos.

Estas circunstancias, dificultan abordar en un artículo de estas características la dimensión del exilio español en Colombia sin caer en una caricatura del mismo basada en una proliferación de fechas y aportaciones sin la contextualización de su significado para el progreso del país de acogida. Por este motivo, hemos optado por seleccionar y desarrollar dos ejemplos de la contribución realizada por los españoles. Se trata de Mercedes Rodrigo Bellido, Diploma en Psicología por la Universidad de Ginebra y Directora del Instituto de Psicotecnia de Madrid, que se convirtió en la introductora en Colombia de la Psicología moderna y en su creadora dentro de la Universidad. Y Manuel Usano Martín, joven médico y profesor de educación física que desarrolló idéntica labor en cuanto a la creación universitaria de los estudios del profesorado de Educación Física y la introducción del Deporte en la Universidad. En ellos, se puede ejemplificar la definitiva aportación que en los más variados ámbitos de la realidad colombiana supuso la llegada del exilio español consecuencia de la Guerra Civil de 1936-1939, con un nexo común a partir de su labor universitaria.

Estos dos españoles pertenecian ya a la elite de la ciencia y la cultura española, ubicados por sus méritos en cierta situación de privilegio en la España de la época. Podemos afirmar que formaban parte de la generación que Francisco Giral $(1994,9)$ denominó como la "Edad de Plata" del pensamiento y la creación intelectual republicana. Los dos fueron becados por la Junta de Ampliación de Estudios e Investigaciones Científicas, como muchos de los otros exiliados españoles que recalaron en Colombia. Gracias a aquellas becas, en el momento de su exilio disponian de una experiencia profesional y un bagaje europeo en sus especialidades que les situaba como miembros de la elite internacional. 
En resumen, la selección del exilio español republicano llevada a cabo en Colombia configuró un grupo con un gran número de integrantes de una elite intelectual, cultural y científica (Martínez Gorroño, 2003). Este aspecto, junto con la estrategia liberal de aprovechamiento de su potencial, aseguraba casi a priori su incidencia definitiva en el progreso del país. Si bien esta labor pionera motivó posteriormente agradecidos homenajes y reconocimientos, también suscitó la firme oposición de ciertos sectores de "colegas" colombianos que veían con recelo su inmediata posición relevante. Las responsabilidades profesionales en manos de "extranjeros" recién llegados, hicieron surgir reticencias acrecentadas por el hecho de tratarse de españoles, circunstancia que rememoraba antiguas y manipuladas rencillas de invasión y conquista y que fue definitivamente funesta e injusta en el caso de Mercedes Rodrigo. El retorno al poder del Partido Conservador (1946), potenció los aspectos hostiles y propició, entre otros efectos imposibles de esbozar siquiera en este artículo, que tras 10 ó 12 años de tenaz trabajo, y realizada la labor más importante con sólidos logros, nuestros dos protagonistas, como muchos otros exiliados en Colombia, se marcharan, no para volver a España, sino para continuar su exilio en otro país americano. Las consecuencias evidentemente injustas que muchos "republicanos" sufrieron por aquellas circunstancias y los momentos de inestabilidad en los que se ha debatido Colombia, no facilitaron la conservación en archivos oficiales de documentación que permitiera fácilmente reconstruir sus trayectorias. El testimonio oral de las fuentes vivas fue definitivo para el rescate de su relevante aportación.

\section{Mercedes Rodrigo Bellido. Sus inicios Y SU ENTORNO SOCIAL}

Mercedes Rodrigo Bellido fue la primera psicóloga española, circunstancia excepcional en una mujer de su época si consideramos los datos del Ministerio de Cultura que recogemos a través de Capel (1982). Al inicio del siglo XX, en España había un 55,8\% de hombres analfabetos y un $71,4 \%$ de mujeres.

Finalizó sus estudios como profesora en Madrid en 1911. Continuó su formación en la Escuela Nacional de Sordomudos Ciegos y Anormales y en el Patronato de Anormales (Herrero, 2005), período que simultaneó con diversos viajes, estableciendo relaciones con los más destacados especialistas europeos. Una beca de la Junta de Ampliación de Estudios e Investigaciones Científicas, le permitió cursar estudios durante 18 meses en Ginebra, en I'École des Sciences de l'Éducation du Institut Jean Jacques Rousseau, dirigido por Claparède.

La influencia de Claperède, y la de Bouvet y Binet, marcaron su vocación profesional. Inició su colaboración con Claparède, fundador de la psicotecnia europea, en el $L a-$ boratorio de Psicología de la Universidad. Allí conoció a Jean Piaget, compañero de estudios con el que inició investigaciones sobre el animismo infantil. Hizo prácticas de enseñanza de anormales ${ }^{3}$ en la Maison des Petits, escuela de prácticas aneja al Instituto, y trabajó en el Gabinete de orientación Profesional (Ibídem). Desde su formación Mercedes Rodrigo mostró una personalidad científica interesada en todas las especialidades de una ciencia naciente: desde la pedagogía práctica a la psicotecnia y la psicología experimental, abarcando tanto la psicología infantil y la psicología de anormales como la orientación profesional.

En 1923 obtuvo su Diploma en Psicología por la Universidad de Ginebra, título que la convertía en la primera mujer Psicóloga española. A su regreso a España fue un miembro fundamental del grupo de la Escuela de Madrid de Psicología. A partir de su influencia ésta adoptó un carácter aplicado, característico de su primera historia, consecuencia de la introducción que Mercedes hizo de los métodos psicotécnicos más modernos aplicados, tanto a la psicología de la inteligencia y escolar, como a la orientación y a la selección profesional. También en 1923 el Ministerio de Instrucción Pública le encargó un curso de "Técnica Psicopedagógica" para maestros (Marin, 1990). Para él preparó, con Roselló, el instrumento que denominaron "Registro Paidológico", que se convirtió posteriormente en una herramienta fundamental para el desarrollo de actividades psicotécnicas subsiguientes y base de investigaciones para diferentes fines y utilidades (Rodrigo, 1933b).

Nacida en Madrid en 1891, podemos afirmar que Mercedes Rodrigo participó activamente y fue parte del movimiento de regeneración que caracterizó aquella etapa de la historia de España, en el que ciertos sectores de intelectuales y científicos se habian empeñado, como consecuencia y tras la crisis del 98 , en la recuperación y la modernización del país. 
Al crearse el Instituto de Reeducación de Inválidos del Trabajo en 1923, fue nombrada responsable de la Sección de Orientación Profesional, especialidad en la que fue verdadera pionera en España (Marín, 1990). En 1925, al ser fundado el Instituto Médico Pedagógico de Madrid, fue nombrada Directora Pedagógica, cargo que desempeñó hasta 1929. En aquella etapa Mercedes Rodrigo fue el centro de referencia fundamental del desarrollo de la Psicología Aplicada en España, tanto en la industria como en las áreas educativa y clínica.

En 1928 se creó el Instituto de Psicotecnia de Madrid, hecho importante en la historia de la ciencia española. La Psicología científica experimentó un gran impulso y comenzó una etapa de éxitos. En este Instituto Mercedes Rodrigo tuvo un importante papel desde su creación. Una situación verdaderamente excepcional en la España de la época: una mujer por sus propios méritos profesionales formaba parte esencial en el proceso de constitución y organización de un centro científico. Rodrigo trabajó como responsable en su estructuración, en la delimitación de los campos de aplicación, en el comienzo del entrenamiento de los profesionales, etc. Con este centro se inició la creación de una red nacional de psicotecnia. Para ello se hizo precisa una formación especializada que se inició en 1929 con cursos específicos para la siguiente generación de psicólogos españoles y para el personal psicotécnico, médico y administrativo que integraría el centro. En todo ello el trabajo de Mercedes Rodrigo fue esencial (Herrero, 2005).

También mostró gran interés por la problemática social de la infancia en su trabajo como psicóloga clínica del Tribunal Titular de Menores, en el Consejo Superior para la Protección de la Infancia y en el Hogar de Delincuentes. Como señala Herrero, fue seguramente la fundadora en 1925 y directora del Comité Español del Libro para el ciego (lbídem).

\subsection{La problemática política española y su incidencia en la trayectoria profesional de Mercedes Rodrigo}

Después del 14 de abril de 1931 y durante la Segunda República y la guerra, como es sabido, concurrieron excepcionales acontecimientos que impulsaron la presencia de la mujer en la sociedad, la cultura y la política. Como señala García Nieto: "La guerra civil impulsó a las mu- jeres a incorporarse al trabajo, al ejército, a la política, y al mundo de la cultura. Se hicieron presentes en toda la realidad social como un factor de transformación." (1982, 42). En ese contexto podemos situar el nombramiento de Mercedes Rodrigo, en 1936, como Directora del Instituto de Psicotecnia de Madrid.

Los dramáticos acontecimientos de la guerra, como el bombardeo sistemático de la aviación alemana sobre la población civil con el objeto de desmoralizar al bando republicano, obligaron al gobierno de la Segunda República a la evacuación de los niños, a fin de alejarlos del frente de Madrid. Como miembro de la Delegación de Evacuación de Madrid, Mercedes Rodrigo participó muy activamente en la organización y control de las evacuaciones, haciéndose cargo de instituciones de auxilio que habian sido abandonadas por sus responsables al inicio de la contienda (Rodrigo, 1933, 1949).

Después de tres años de guerra y del triunfo del golpe de estado, como es sabido, medio millón de "republicanos" tuvieron que exiliarse para huir del acoso de leyes como la de Responsabilidades Políticas, del 9 de febrero de 1939, en cuyo artículo n. ${ }^{\circ} 1$ se decía: "Se declara la responsabilidad política de las personas, tanto jurídicas como físicas, que desde el $1 .^{\circ}$ de octubre de 1934, y antes del 18 de julio de 1936, contribuyeron a crear o a agravar la subversión de todo orden de que se hizo victima España y de aquellas otras que a partir de la segunda de aquellas fechas se hayan opuesto o se opongan al Movimiento Nacional con actos concretos o con pasividad grave".

Mercedes Rodrigo tenía 48 años cuando, por su apoyo a los impulsos democráticos y su participación en instituciones de la Segunda República, se vio obligada al exilio. Su hermana María, prestigiosa compositora musical, se exilió con ella, así como José García Madrid, de 32 años, quien podemos afirmar que a partir de aquel momento se posicionó como un hijo para las dos hermanas $y$, conformados como una suerte de original familia, compartieron todo su devenir en los varios exilios sufridos. Los contactos de Mercedes en Suiza facilitaron, posteriormente, la salida de Francia y su viaje a Colombia, eludiendo los problemas europeos ante la proximidad de la Segunda Guerra Mundial.

A través de fuentes orales, como Ramón González (1998), pudimos saber que Mercedes Rodrigo había conocido en 
Suiza a Agustín Nieto Caballero, Rector de la Universidad Nacional de Colombia, quien contribuyó a facilitar su viaje a Bogotá, conocedor de la preparación profesional y el gran prestigio que ya tenía Mercedes en los sectores especializados. A la llegada a aquel exilio, Ramón González había tenido la oportunidad de convivir como el miembro más pequeño de la familia Prat García ${ }^{4}$ con las hermanas Rodrigo y con José García Madrid, compartiendo vivienda por las dificultades económicas que padecieron. Con el tiempo Ramón González cursó en Bogotá estudios de Medicina en la Universidad Nacional y colaboró con Mercedes Rodrigo como ayudante.

\subsection{Su trayectoria en Colombia}

En 1939, las mujeres colombianas apenas tenían presencia en la universidad, ni siquiera como alumnas. Sin embargo, Mercedes Rodrigo, gracias al apoyo de Nieto Caballero, que supo conocer y valorar la oportunidad que ofrecía su especial y única cualificación, le asignó la dirección de la Sección de Psicotecnia que se creó especialmente a su llegada y con el objetivo de que ella pudiera encabezarla. Ésta se ubicó en la Facultad de Medicina, dentro del Departamento de Fisiología dirigido por el profesor Esguerra Gómez, quien estuvo de acuerdo en afrontar el riesgo de introducir a una mujer al frente de aquella Sección, cuya función primera debía ser hacer la selección de alumnos para entrar en la Universidad Nacional.

Para que pueda percibirse lo excepcional de la circunstancia que rodeó a Mercedes Rodrigo en aquella Universidad y en todos los ambientes en los que se desenvolvió en aquel momento, ofreceremos tan sólo unos significativos aspectos de la situación de gran marginación en la que la mujer se encontraba en aquel país. Junto a las altas tasas de analfabetismo ${ }^{5}$, otros aspectos nos pueden dar cierta visión de sus condiciones. Así, podemos documentar la radical oposición a la educación de la mujer que mantenían con gran beligerancia los altos responsables de la Iglesia católica colombiana. Sirva como ejemplo que "el obispo de Pasto lanzó una condena de excomunión en el año 1936 contra la universidad de Nariño, porque en sus aulas estaban presentes varias mujeres estudiantes" (Velásquez Toro, 1989, 28), lo cual constituía desde su perspectiva un peligro social.

En 1933, la enseñanza secundaria para los varones era diferente de la que se ofrecía a las mujeres que no les servía para acceder a la universidad (Ibídem). "La primera mujer bachiller fue admitida en la Universidad Nacional en el año 1936, pero fue en 1937 cuando ingresó el primer grupo de mujeres en esa institución" (Ibídem, 29).

Mercedes Rodrigo contó con el apoyo de un sector minoritario del Partido Liberal, grupo que en su mayoría mantenía posiciones de gran discriminación respecto a la mujer, pero que aceptó aquella circunstancia verdaderamente excepcional, condicionada, con toda probabilidad, por la imposición de ciertos miembros de la elite cultural y política, como Nieto Caballero o el mismo Eduardo Santos, que sin duda imponían sus criterios "más aperturistas" en beneficio del progreso del país. Por su parte, el partido Conservador se oponía a la acogida de los exiliados españoles al considerarlos un grupo con ideología de izquierda, opuesta a sus criterios políticos y religiosos, aspecto que en el caso de una mujer a la que se adjudicó una responsabilidad de gran compromiso, nos acerca a la idea de la situación verdaderamente comprometida que aceptó aquella exiliada española. En aquel contexto, la selección de alumnos para su entrada en la Universidad, suscitó entre los conservadores una tenaz oposición, al establecer el ministerio el examen oficial obligatorio para el ingreso en las universidades, y darse además la circunstancia de que al frente de esa selección se encontraba la psicopedagoga española Mercedes Rodrigo llegada al país como exiliada (Jaramillo, 1989, 101). Por otra parte debemos apuntar que aquel cometido que se le asignó, ya partía en su génesis con una problemática previa que a priori se sabía delicada, ya que pretendía establecer criterios racionales y "objetivables" para acabar con las arbitrariedades con que se había venido resolviendo tradicionalmente el ingreso de los alumnos a los centros universitarios estatales.

No obstante, el grupo liberal no dudó en utilizar sus servicios, aun sabiendo el riesgo y la oposición a la que se enfrentaba. Su preparación suponía una oportunidad excepcional para utilizar los modernísimos recursos de la Psicotecnia, así como para organizar la Psicología en la Universidad Nacional e introducirla en el pais. Fue un hito pionero en toda Hispanoamérica.

Mediante la aplicación de test y pruebas psicotécnicas, llevó a cabo su trabajo. Demostró una gran dedicación y entusiasmo, características de toda su trayectoria vital, alcanzando gran prestigio entre los sectores intelectuales. 
En enero de 1940 se realizaron ensayos con aspirantes a ingresar en varias facultades y con alumnos de tercer año de Medicina. Entre las pruebas aplicadas las fuentes orales recordaron: el Army Alfa, una prueba de cultura general, el test de Toulouse-Pieron (sobre atención), el test de aptitud Médica de Moss, Hunter y Hubband, adaptado al medio colombiano (aplicado sólo a estudiantes de Medicina), el Thurstone de Inteligencia Lógica (para Derecho), y el de Inteligencia Espacial de Donaiewey (para Ingenieria).

Este trabajo pionero de Mercedes Rodrigo, en 1940, situaba a Colombia a la cabeza de los países más adelantados en aquellas técnicas científicas, las más modernas incluso en Europa. Para ella supuso una labor previa de gran dificultad que tuvo que efectuar en solitario, para adecuar y adaptar al medio colombiano todas las pruebas. Para tal fin,

\begin{abstract}
"Mercedes Rodrigo se rodeó de gente muy buena [muestra] en su trabajo de adaptación de los test al país. Llevó a cabo unos test de inteligencia para determinar el coeficiente intelectual. Hizo unas pruebas entre ellas a un gran profesor, musicólogo y profesor de ingeniería Otto de Greiff. Tenía un altísimo coeficiente. Hizo pruebas a él y a otros como modelo. Recuerdo que se la hizo a Juan Jacobo Muñoz (que fue Ministro de Sanidad), a Gonzalo Echeverri (también médico-ginecólogo), a Alejandro Jiménez Arango (que también fue ministro), a Mario Gaitán Yanguas (oncólogo y radioterapeuta), a Santiago Londoño, y a varios otros que lamento profundamente no recordar ahora sus nombres, todos personas muy notables. Mercedes les llamaba "mis superdotados". "El tipo de pruebas era totalmente nuevo en Colombia" (González, 1998).
\end{abstract}

El procedimiento de selección, junto con otros ensayos psicométricos adaptados, fue extendido después a la Escuela Superior de Enfermeras, al Instituto Pedagógico Nacional, a la Escuela Normal Superior, y a otras escuelas públicas y privadas. También se transformó el proceso común de selección de personal en instituciones públicas, como la empresa del Tranvía Municipal de Bogotá o la Policía Nacional (Mankeliunas, 1993).

Ramón González, joven exiliado español, colaborador en la corrección de pruebas, y, con el tiempo, titulado en medicina por la Universidad Nacional, nos relataba algunos recuerdos sobre las dificultades de aquella delicada responsabilidad acometida por esta mujer exiliada, aunque arropada por la estructura universitaria liberal:
"Alfonso Esguerra Gómez era entonces profesor de Fisiología y tenía mucho interés y aprecio por Mercedes Rodrigo, conocía su gran competencia y la posibilidad de aplicar las técnicas psicotécnicas... Todos los procedimientos se iniciaron en el departamento de Fisiología de la Facultad de Medicina y figuraba como director el profesor Esguerra, por varias razones. Por su prestancia, por la importancia que daba a nuevos métodos y por asumir él la responsabilidad frente a los ataques de la prensa conservadora contra los exiliados 'rojos' que deberían hacer los exámenes de admisión a la Universidad. Los 'cupos' eran pocos y muchas las solicitudes. Las admisiones se producian con rigurosa imparcialidad, previas calificaciones muy técnicas y objetivas. Santiago Londoño era el Jefe del grupo de examinadores de la sección. Era un hombre de una gran integridad que mantenía una gran independencia frente a todas las presiones. A la cabeza de todo el trabajo estaba Mercedes Rodrigo".

Los resultados le confirieron gran prestigio entre los sectores interesados en el avance científico, el progreso y la modernización. Bajo su dirección se fue consolidando en años sucesivos la selección de alumnos. Se fueron recogiendo frutos en la ciencia y la investigación colombianas. Así, Esguerra Samper en 1944 para el grado de Doctor en Derecho elaboró en la Sección de Psicotecnia su tesis sobre "El testimonio", con personal de la Policía Nacional. Melo Rico en 1948 presentó su tesis de Doctor en Medicina sobre pruebas psicológicas con aspirantes a la Universidad Nacional.

En el ámbito educativo, Mercedes Rodrigo hizo los primeros ensayos psicométricos, con fines de orientación profesional, en colegios como el Gimnasio Moderno, el Instituto Pedagógico, la Escuela de Enfermeras, o la Escuela Industrial. Inició la trayectoria de la psicología industrial, experimental y social, con investigaciones en la fábrica Bavaria y la empresa del Tranvía Municipal de Bogotá. Estos trabajos eran los primeros en toda Hispanoamérica en la psicología aplicada, tanto al ámbito de la educación, como en los sectores industrial y profesional, siendo el origen de todas las investigaciones posteriores (Martínez Gorroño, 1999).

Su prestigio varió el panorama nacional con respecto a la psicología. Con el aumento de la demanda se hizo necesario formar psicólogos. Con este fin se creó el Instituto de Psicología Aplicada de la Universidad Nacional, primer 
centro superior de formación universitaria de psicólogos, por acuerdo 231 de 1947 (Martínez Gorroño, 1992). Mercedes Rodrigo organizó y llevó a cabo, tanto la estructura de este Instituto como el plan de estudios (Martínez Gorroño, 1990).

La historiografía colombiana especializada resumía en estos términos la labor de Rodrigo Bellido:

\begin{abstract}
"No es preciso insistir en su labor como organizadora, como administradora, así como catalizadora de inquietudes. Fue ella quien estandarizó los primeros test en Colombia, quien hizo los primeros planes de estudios para psicólogos, quien entusiasmó a la gente por la psicología y sus potencialidades". "Estructuró la psicología colombiana, le dio su forma actual, y entrenó a quienes iban a convertirse en los líderes de la psicología de las siguientes décadas" (Ardila, 1973, 31).
\end{abstract}

Su estancia en Colombia fue muy activa en sus contactos internacionales. Era requerida y considerada en los foros más prestigiados de la psicología científica. En 1947 viajó a Estados Unidos. A su vuelta sus escritos muestran cómo efectivamente el Instituto de Psicología Aplicada, obedeció a las propuestas y la estructura que sólo ella gestó.

\begin{abstract}
"Al regreso de mi reciente viaje realizado a Estados Unidos por especial invitación de la American Psychological Association y por tanto de haber tenido ocasión de conocer de cerca los enormes avances de la Psicología en los momentos actuales, nos hemos podido dar cuenta de que nuestra modesta Sección de Psicotecnia ha seguido hasta ahora normas seguras para su desenvolvimiento y está ya, hoy en día, en capacidad de ampliar sus servicios para seguir el ritmo acelerado con que por todas partes se imponen las aplicaciones de la psicología. En consecuencia, creemos conveniente proponer las ampliaciones y modificaciones siguientes:

Conversión de la Sección en Departamento, término este último más frecuentemente empleado en los medios americanos y al mismo tiempo cambiar la palabra 'psicotecnia' más empleada en Europa, por el de 'psicología aplicada', igualmente más usado en América del Norte. Organizar el trabajo dentro del Departamento de Psicología aplicada en las siguientes secciones: Sección de infancia y adolescencia: para estudio general, casos individuales, orientación profesional, selección y clasificación de anormales, corrección de defectos del lenguaje y dificultades en el aprendizaje de la lectura. Selección de superdotados. Una clínica psicológica... Sección
\end{abstract}

universitaria para exámenes de ingreso a la Universidad, servicio de consultas de estudiantes... Secretaría... Sección de investigación. Preparará todas las técnicas... calificación... cálculos estadísticos... Sección psicomédica, con un psiquiatra y un especialista en técnicas psicodiagnósticas... Sección de enseñanza, dedicada, en primer lugar a la formación de personal que de ahora en adelante piense especializarse en psicología aplicada, organizada en años sucesivos como profesión independiente con miras a ir cubriendo los puestos que se pueden ir creando en distintos lugares de la república... Bogotá, noviembre 5 de 1947. Mercedes Rodrigo. Directora" (Rodrigo, 1949).

Bajo esta estructura concebida por Mercedes Rodrigo inició su funcionamiento el citado Instituto de Psicología Aplicada creado en 1947. Sólo se cambió el nombre de Departamento por el de Instituto. De él salieron, en 1952, los primeros 11 Psicólogos graduados en una Universidad colombiana.

Carney Landis, psicólogo de la Universidad de Columbia, visitó Bogotá en octubre de 1948 como integrante de una misión médica del Unitarian Service Comité de EE.UU. Visitó el recién creado Instituto y presentó un informe muy positivo del mismo, insistiendo en su importancia para el país y la conveniencia de darle apoyo: "Su plan actual de organización se compara favorablemente con el de cualquiera de las más progresistas universidades americanas... Los esfuerzos de la señora Rodrigo para establecer clínicas de higiene mental, orientación a la infancia y procedimientos similares para los grados más bajos de las escuelas públicas, merecen cuidadosa consideración y apoyo..." (Carney Landis en Ardila, 1973, 33).

Mercedes Rodrigo desempeñó también una importante labor docente. Desde 1945 fue profesora de Psicología en la Escuela Nacional de Enfermeras y en la Escuela Normal Superior de Bogotá. En la Universidad Nacional enseñó Psicopedagogía. En 1946 se creó la cátedra de Psicología Médica dentro de la Facultad de Medicina y fue encargada de su docencia. Fruto de este trabajo fue su libro Introducción al Estudio de la Psicología (1949), obra que dedica una especial atención a la psicología evolutiva y a los tests para la infancia.

Otro hito en Bogotá supuso la fundación del "Instituto García Madrid" para niños anormales, primer centro de 
educación especial de Colombia y una de las primeras instituciones en Psicología clínica que funcionó entre 6 y 8 años, promovida por Mercedes Rodrigo y José García Madrid. Personalmente nos permitimos el comentario de ver en la creación de aquel Instituto, el respaldo que Mercedes siempre pareció suponer para aquel "hijo" de ambas hermanas, que para aquella fecha ${ }^{6}$ ya debía tener adelantados o ultimados con su apoyo los estudios de Medicina en la Universidad Nacional, que le permitieron su ejercicio profesional como Psiquiatra, convirtiéndose en el principal colaborador de Mercedes.

En 1946, la llegada al gobierno de los conservadores cambió las circunstancias para los exiliados españoles. El paulatino incremento de la violencia, provocado por el enfrentamiento armado entre los partidos y la radicalización de algunos sectores alcanzó una crisis máxima el 9 de abril de 1948, con el asesinato del líder liberal Jorge Eliécer Gaitán y la insurrección popular conocida como el "bogotazo".

En 1950 alcanzó el poder Laureano Gómez conservador radical que había liderado una tenaz campaña contra la acogida de los exiliados españoles desde su diario El Siglo. En sus páginas el 27 de noviembre de 1948 preguntaba “¿Cuál de los dos partidos abrió las puertas de la nación a la emigración roja española?". Los exiliados eran señalados como propiciadores de las revueltas populares.

Varios profesores españoles de la Universidad Nacional, se vieron obligados a abandonar sus puestos. La pertinaz oposición de los conservadores a los exámenes de selección, tuvo como resultado los hechos que citamos a través de dos autores colombianos: "La psicóloga Rodrigo salió de Colombia en 1950, acusada de ser comunista" (Ardila, 1973, 30). "Las pruebas psicológicas para la selección de los aspirantes universitarios fueron blanco de las embestidas por parte de algunos sectores del país, y el problema fue llevado hasta el Congreso Nacional. El problema surgido con la señorita Rodrigo llegó a sus últimas consecuencias con su expulsión del país en 1950" (Villar Gaviria, 1965, 9).

La situación a nivel personal fue testimoniada por las fuentes orales como verdaderamente traumática y era recordada con gran tristeza la situación de indefensión y desamparo que como exiliada política Mercedes Rodrigo padeció por la simple circunstancia de haber cumplido con el deber que le había sido encomendado por aquellos que para ello la habian acogido. Ramón González rememoraba en su testimonio la desolación de dos mujeres mayores que se veían abatidas ante aquella situación que las desbordaba y recordaba en aquel momento a José García Madrid, en su papel de "sostén" de aquellas dos hermanas agobiadas por la desolación: "La orden de expulsión del país fue notificada a las hermanas Rodrigo y a José García Madrid por personal de la policía nacional en el apartamento en que vivian, en las primeras horas de la noche. No fue nada agradable. La expulsión de esta mujer supuso un retroceso. Mercedes era pionera en la psicología y en todos estos campos en Colombia" (Martínez Gorroño, 1999, 22).

El Instituto de Psicología Aplicada dejó de prestar gran parte de sus servicios y apenas si mantuvo su existencia nominal. No se graduaron psicólogos en 1953, en 1954 se titularon 5, y 6 en los años 1955 y 1956. Las cifras mínimas no se superaron hasta la década de los setenta ${ }^{7}$. Las pruebas de admisión a la Universidad no fueron reorganizadas sino dos décadas más tarde. Las funciones de investigación en educación no se reanudaron hasta 1968... Aunque muchos años después, hemos podido documentar que la Federación Colombiana de Psicología en 1970 concedió a Mercedes Rodrigo el Premio de Psicología. En su citación se añade: "por su labor pionera a favor del desarrollo de la psicología científica y profesional en Colombia".

\subsection{Sus últimos años en Puerto Rico}

Mercedes fue expulsada de Colombia con 59 años, su hermana María tenía 62. Aunque la situación fue dramática, también por fuentes orales sabemos que se resolvió a través de los contactos que como médico psiquiatra ya tenía García Madrid y que propiciaron su marcha hacia Puerto Rico.

Alli Mercedes trabajó como profesora de educación en la Universidad de Río Piedras, aún no existían los estudios de psicología en aquel país. Desde 1955 trabajó en la consulta de la "Administración de Veteranos" de Estados Unidos, prestando apoyo psicológico a los excombatientes. Aunque continuó con investigaciones en psicometría (Ardila, 1988) su actividad se centró en terapias clínicas individuales y de grupo. También trabajó en una clínica privada de San Juan hasta 1972, cuando se retiró por su avanzada edad y por problemas físicos. 
Fue fundadora de la Asociación de Psicólogos de Puerto Rico, afiliada a la American Psychological Association, desde su inicio en 1954, vocal primero, y presidenta en 1958 (Roca, 1993).

Las hermanas Rodrigo vivieron en Puerto Rico como una familia con su "hijo" José. En su casa habitó el poeta español Juan Ramón Jiménez, después de la muerte de Zenobia de Camprubí, y de quien se ocuparon hasta su fallecimiento. Después de la muerte de su hermana María, Mercedes comenzó a padecer trastornos mentales. Con el tiempo una invalidez total la hizo vivir sus últimos años bajo la dependencia de José García Madrid y de su esposa.

\section{Manuel Usano Martín y la orientación MOdernizadora de la Educación Física y el Deporte español en la Segunda República}

Durante las primeras décadas del siglo XX la Educación Física que se impartía en los centros de enseñanza españoles, como en todo el resto de la Europa continental, seguía influida por los métodos gimnásticos de las tres escuelas surgidas en el siglo XIX: la amorosiana o francesa, la alemana y la sueca. Simultáneamente la actividad física conocida como "Sport" se había ido desarrollando en el Reino Unido como una alternativa de "Educación Física", a partir de la iniciativa de Thomas Arnold en Rugby ${ }^{8}$ y de su difusión en los centros escolares de las islas británicas. El deporte iniciaba sus primeras influencias en el "viejo continente" a finales del XIX, pugnando por convertirse en una forma de actividad corporal más motivadora en las escuelas, potenciada por el empeño de promotores entusiastas de la obra de Arnold como fue Pierre de Coubertin (1863-1937).

Esta corriente "moderna" de influjos ingleses, que contestaba, ya al final del siglo, principalmente a la gimnástica sueca como sistema hegemónico en las escuelas del continente, marcó las futuras orientaciones del área y avanzado el siglo XX, el deporte se convirtió en la forma más habitual de cultura física de nuestras sociedades. En España, esta nueva tendencia comenzó un incipiente desarrollo durante las décadas de los veinte y los treinta, ligada a las nuevas orientaciones pedagógicas vinculadas con instituciones de planteamientos progresistas y krausistas de educadores y profesores cercanos a los aires renovadores de la Institución Libre de Enseñanza (ILE). Así, en nuestro país esta nueva forma de Educación Física a través del Deporte, tuvo su primera repercusión académica en la ILE, a partir de la contratación en 1882 del profesor inglés Capper, que introdujo aquellas formas de juegos ingleses y, según López Serra (1998), desde 1889, concretamente el foot-ball.

La conexión de la ILE con la tendencia "renovadora" que suponía la corriente deportiva puede igualmente documentarse a través de sus conexiones con el naciente Movimiento Olímpico. Efectivamente, la ILE fue la única institución representada en el conocido por la historiografía especializada como Congreso de la Sorbona para la restauración de los Juegos Olímpicos, en el que estuvieron presentes tres profesores institucionistas miembros en aquel momento de la Universidad de Oviedo: Adolfo González Posada, Aniceto Sela y Adolfo Buylla (Magdalena, 1992).

Igualmente bajo la influencia de la ILE, ya en el período correspondiente a la Segunda República, se iniciaron los primeros impulsos para organizar la formación del profesorado de Educación Física en la universidad. Así se creó en España el primer centro civil para formación del profesorado universitario de Educación Física, por iniciativa de Domingo Barnés Salinas (1879-1940), Ministro de Instrucción Pública y Bellas Artes, discípulo y miembro de la ILE ${ }^{9}$. Por Decreto publicado en la Gaceta de Madrid n. ${ }^{\circ} 348$, del jueves 14 de diciembre de 1933, y con la denominación de Escuela Nacional de Educación Física (ENEF), integrada en la Universidad Central de Madrid, se hizo depender de la Facultad de Medicina, dentro de la que funcionó, y de la sección de Pedagogía de la Facultad de Filosofía y Letras. En el preámbulo del citado Decreto de creación se hacian constar varias consideraciones, entre las que destacamos: "La necesidad de organizar la educación física en los centros de enseñanza, para lo que es de capital importancia resolver el problema fundamental del profesorado" (Gaceta n. 348, 14-XII-1933, pág. 1810).

Aquel primer impulso universitario relacionado con lo que hoy es la especialidad de las Ciencias de la Actividad Física y el Deporte, adquiere una especial significación y supuso un hito histórico en nuestro país, pues aunque el Decreto calificaba de provisional el Plan de Estudios de la Escuela, y lo considera "ensayo", fue la primera vez que la formación del profesorado de Educación Física se incluía 
en la estructura universitaria y los requisitos de ingreso consignados en el artículo quinto estaban marcados por estar en posesión del título de Bachiller o el de Maestro de Primera Enseñanza. Ello permitió el desarrollo de un programa de nivel académico con rango universitario en el que se ubicaba, y que nunca antes había alcanzado en nuestro país. Como tantos otros proyectos e inicios modernizadores se quedó en suspenso con motivo de la Guerra Civil $^{10}$ (Fernández Nares, S., 1993, 139).

Manuel Usano, nacido en Arévalo (Ávila) en 1909, Licenciado en Medicina y Cirugía en la Universidad de Valencia en 1932, estuvo entre los primeros estudiantes de Medicina que obtuvo el título de profesor de Educación física. Así, figura en sus curricula como Profesor de Educación Física desde 1932 y entre ese año y 1939, consta como Profesor Especial de Educación Física, por concurso, del InstitutoEscuela de Valencia en cuya fundación también participó.

El Instituto-Escuela de Madrid, creado en 1918, como es sabido, fue un experimento educativo para la segunda enseñanza que trató de llevar a la educación oficial los principios pedagógicos de la ILE. La experiencia del Instituto-Escuela madrileño influyó en la creación de otros centros en Barcelona, Sevilla y Valencia. Manuel Usano, como ya hemos citado, trabajó en la creación de este último. Este aspecto, junto con la circunstancia de que también fue becario de la Junta para la Ampliación de Estudios e Investigaciones Científicas, de idéntica inspiración, nos le presenta como un claro institucionista $y$, como expondremos, totalmente integrado en aquella corriente renovadora de la educación señalada en los párrafos anteriores.

La oportunidad de obtención de aquella nueva titulación que Manuel Usano obtuvo simultáneamente a sus estudios de Medicina estuvo posiblemente motivada por su gran afición a la actividad física. Fue durante toda su juventud un gran aficionado al deporte y un deportista en varias especialidades atléticas. Los testimonios de su familia, la documentación de su archivo y múltiples fotografías de su álbum personal lo testimonian. En su trayectoria académica se ven patentes las tendencias que en aquellos años intentaban "modernizar" el área de la Educación Física en Europa y que se habian introducido en el país a partir de las metodologías implantadas en la ILE y que iba impulsando el Movimiento Olímpico en todo el continente promovido por el barón de Coubertin.
Teniendo en cuenta todos estos aspectos, aunque no existe constancia documental, suponemos que Manuel Usano debió participar o estar muy cercano a la creación de la Escuela Nacional de Educación Física (ENEF), aunque la fecha de su título 1932, no se ajusta a los datos de que disponemos. Es posible que dada su condición de Maestro de Primera Enseñanza y su conexión con los inspiradores de la iniciativa, pudiera haber seguido un cauce simultáneo en algún proyecto piloto y cumplir las pruebas de suficiencia que se establecían en el artículo 5 del Decreto de 1933. En dicho artículo se hacía constar que para la obtención del título, "será necesario hacer sus estudios y pruebas de suficiencia de las asignaturas de Anatomía y Fisiología de la Facultad de Medicina", materias que según su expediente superó en el curso 1928-29 en sus estudios de la licenciatura en Medicina.

Todos estos aspectos fueron confiriendo un perfil específico al currículo profesional de Manuel Usano que se fue orientando entre la medicina, la actividad física y el deporte con una especialización hacia la fisiología. Su exitosa trayectoria académica le permitió disfrutar de una beca de la Junta de Ampliación de Estudios en mayo de 1933. Como consecuencia, durante un año cursó estudios en Alemania sobre Fisiología del Deporte y del Trabajo y se matriculó en la Escuela Superior de Educación Física de Alemania, en Berlín (Deutsche Hochschule für Leibesübungen). También asistió al curso anual de especialización médico-deportiva organizado por la Dutsche Sportärztebund, que superó con éxito, obteniendo el certificado como Sportarzt (Médico Deportivo).

Como profesional en España fue Profesor Ayudante de clases prácticas de las Cátedras de Bioquímica y Fisiología en la Facultad de Medicina de Valencia desde 1932 hasta su exilio. El curso 1934-35, había impartido Bioquímica y Fisiología General en la citada Facultad, trabajo que había simultaneado con el ya citado de profesor de EF en el Instituto Escuela de aquella ciudad.

Entre 1928 y 1935 Manuel Usano fue Director del Comité Deportivo de la Universidad de Valencia, desde aquella responsabilidad promovió la organización del deporte universitario. Sobre las innovaciones e investigaciones de aquellos años encontramos en su archivo que la Universidad de Valencia le solicitó un proyecto que presentó en 1933: "Un tipo de campo de deportes moderno". 
Su compromiso deportivo no se limitó a los ámbitos universitarios, sino que también alcanzó el entorno federado. Fue Presidente de las Federaciones de Atletismo, Natación y Rugby de Valencia en diversos períodos y campeón universitario en varias ocasiones, de decatlón, atletismo, fútbol y rugby.

Por la orientación profesional y especialización con que Manuel Usano iba encauzando su trayectoria se propiciaron circunstancias como la de que fuera el Delegado Oficial de España en el 1. ${ }^{\text {er }}$ Congreso Internacional de Medicina del Deporte, celebrado en 1933 en Turín y Roma (Italia). La presencia española de Usano Martín en un evento que reunía por primera vez a expertos de una especialización tan novedosa en la época, nos da idea de las caracteristicas tan específicas del aquel español, así como de su ubicación dentro de las más modernas tendencias europeas que modernizaban, impulsaban y daban respuestas a las necesidades de las demandas de los países más avanzados del momento. Su contribución a este congreso fue un trabajo titulado: "Ficha fisiológica y de orientación deportiva", que por su interés y originalidad fue publicado en las Actas de aquel primer Congreso Internazionale de Medicina dello Sport.

Entre 1932 y 1939 Manuel Usano fue también Médico-Jefe del Departamento de Fisiología del Deporte y Biometría deportiva de la Universidad de Valencia. Este período supuso la orientación de su especialización científica hacia la Fisiología, en su aplicación al trabajo, alimentación y ejercicio físico, bajo la dirección del Dr. José Puche Álvarez, Catedrático de Fisiología y Bioquímica de aquella universidad. Fruto de sus investigaciones durante esta etapa fueron varias publicaciones en coautoria con el Dr. Puche en Crónica Médica de Valencia. En la revista de Barcelona Mundo Deportivo, como autor único publicó en 1936 dieciséis artículos de divulgación científica sobre "Medicina del deporte".

Simultáneamente a su trabajo como Profesor Ayudante de Cátedra de Fisiología con el Dr. Puche, estuvo realizando trabajos de investigación encaminados a su tesis doctoral, que culminó y presentó bajo el título de "Tipos de reposición del corazón en relación con el ejercicio muscular", en torno a las fechas en que surgió la contienda civil. Los recuerdos de su esposa sobre aquellas circunstancias fueron los siguientes: "Cuando estalló la guerra había presentado la tesis para el título de doctorado, aunque él ya estaba en la Facultad de Medicina de ayudante del Dr. Puche en Valencia, Profesor Ayudante de Cátedra de Fisiología, entonces entre tanto estuvo preparando la tesis y la presentó cuando estalló la guerra. Se debió quedar por ahi en algún archivo de algún centro"'1.

Después del final de la guerra, ya en Francia, su especialización en Fisiología le sirvió para retomar contactos profesionales y conseguir un modo de subsistencia. Después de realizar múltiples trabajos eventuales de todo tipo, en Toulouse entre 1939 y 1940 fue colaborador de Camil Soula, Profesor de Fisiología de la Facultad de Medicina y también Director del Instituto de Educación Fisica de aqueIla Universidad, centro en el que Manuel Usano prestó su colaboración en torno a la Fisiología del Deporte. A pesar de su breve estancia, el interés de su trabajo motivó que en ese mismo año la Universidad de Toulouse publicara su trabajo "Fiche physiologique type".

Como otros muchos exiliados refugiados en Francia, se encontró con un problemática diversa y tortuosa a la que se añadieron los prolegómenos de la contienda mudial, motivo que le impulsó a buscar la posibilidad desesperada de partir a tierras americanas, a través de los compatriotas que ya se encontraban al otro lado del Atlántico. Así la familia Usano, en espera de los visados que el Dr. Puche gestionaba desde México, permanecieron seis meses en Burdeos. Las deplorables condiciones de vida que se ofrecían a los españoles exiliados en aquella ciudad, les indujeron a trasladarse a Toulouse, a pesar de los riesgos que implicaban los viajes por la carencia de documentación y el peligro que suponía la posibilidad de ser detenidos y enviados a un campo de concentración.

Los azares burocráticos propiciaron la llegada en primer lugar de la documentación que tramitó en Bogotá José María Ots Capdequí, quien había sido compañero de Manuel Usano en la Universidad de Valencia y destacado historiador del Derecho Indiano, en aquellas fechas ya exiliado en Colombia. Su prestigio como profesor e investigador le había hecho ser invitado personalmente por el Presidente liberal Eduardo Santos para ubicarse en aquel país. AqueIla posición de cierta "garantía" le sirvió para "avalar" la entrada de otros españoles republicanos.

La evolución de las circunstancias políticas europeas, fueron la causa de que la familia Usano no esperase la po- 
sibilidad de la llegada de los visados que le permitirían la entrada en México, por lo que partieron de inmediato a comienzos de 1940 desde Marsella en un barco denominado "Commisaire Ramel", el último que partió de aquel puerto francés antes del inicio de la Guerra Mundial.

\subsection{El primer impulso en la formación del profesorado de Educación Física en la Universidad de Colombia}

La política del presidente liberal Eduardo Santos (19381942), estuvo marcada por la misma preocupación de impulso educativo que la de su predecesor Alfonso López. Como consecuencia, ciertos políticos liberales empezaron a observar como una oportunidad para Colombia el exilio que, procedente de las guerras y los totalitarismos europeos, se estaba produciendo como consecuencia de la presión que ejercian sobre los sectores de ciencia y cultura que se adscribian a ideologías y posturas democráticas.

A su llegada a Colombia, Manuel Usano intentó ubicarse profesionalmente como médico. En España, aunque la Guerra Civil y sus circunstancias habian truncado por escasas fechas su doctorado, había concluido sus estudios de Licenciado en Medicina y Cirugía en 1932 y desde el 5 de julio de 1934 había sido admitido como colegiado $n$. $^{\circ}$ 2.342 en el Colegio de Médicos de Valencia. En aquella universidad, y con el objetivo de introducirse como profesor universitario, había continuado sus estudios para doctorarse y había realizado el examen de Grado en 1932 con calificación de sobresaliente. También tenía ya experiencia profesional en la práctica como Médico-Interno del Hospital Clínico de la Facultad de Medicina de Valencia. Pero sus intentos por la convalidación de su título se vieron frustrados con la circunstancia de que todos los graduados en medicina en Colombia lo hacian como doctores.

Por otra parte, las necesidades de Colombia no facilitaban precisamente la convalidación de la titulación y la experiencia médica de Manuel Usano Martín. Sin embargo, su especialización como Profesor de Educación Física hizo surgir un punto de confluencia con el interés colombiano de docentes cualificados demandados por las autoridades liberales. Así, inició su trabajo profesional en esa área $y_{\text {, }}$ como expondremos, desempeñó una labor de interés clave para las necesidades y carencias de la Educación Física y el Deporte de Colombia.
Manuel Usano consiguió trabajo en el Instituto Nacional de Educación Física de Colombia (Bogotá). El 14 de agosto de 1940 comenzó la impartición de clases como Profesor de Fisiología, Kinesioterapia, Biometría y Atletismo, además de ser nombrado Jefe de los Laboratorios de Investigación y Prácticas. Este primer paso motivó, por una parte, el abandono provisional de la medicina como ámbito laboral y, por otra, encauzar su vida profesional en el campo de la enseñanza de la Educación Física y en el del Deporte en general. Así, muy pronto, en 1941, fue nombrado Director Técnico del equipo atlético de Cundinamarca $^{12}$ en los $V$ Juegos Atléticos Nacionales de Colombia en los que el equipo resultó vencedor. Ese mismo año fue designado Director de Educación Física y Deportes de la Escuela Militar de Cadetes de Colombia, cargo que simultaneó con su trabajo en el Instituto de Educación Física hasta 1942.

Con su incorporación en 1940 al Instituto Nacional de Educación Física, Manuel Usano se introdujo en el único centro colombiano que había intentado en el país la preparación de docentes especialistas con respaldo estatal. Había sido creado por iniciativa del gobierno liberal de Alfonso López Pumarejo en 1936 tras la contratación, mediada la década de los treinta, del profesor chileno Candelario Sepúlveda Lafuente, en un intento por cubrir las deficiencias que en el entorno educativo se observaban.

Cuando Usano se incorporó a aquel Instituto Nacional de Educación Física, su existencia se mantenía a duras penas, con toda probabilidad por la carencia de profesores cualificados. Así puede entenderse la cantidad de materias y responsabilidades que inmediatamente le fueron adjudicadas $^{13}$. El centro impartía, según Contecha Carrillo (1999), estudios de dos años de duración y formaba profesores de Educación Física, entrenadores, instructores, masajistas, administradores deportivos.

Usano Martín debió suponer un verdadero descubrimiento para las autoridades educativas colombianas, con respecto al potencial que en el campo de la Educación Física podía suponer. Su trayectoria profesional ofrece un paralelismo muy similar a la de otros republicanos, que como él ofrecian al país preparación y experiencia en diferentes campos que aún estaban por desarrollar, como fue el caso de Mercedes Rodrigo, expuesto en los apartados anteriores de este mismo trabajo. 
Así con respecto a la Educación Física las autoridades liberales actuaron de forma similar a como ya lo habían hecho en otras especialidades, creando y promoviendo instituciones en base a los "recursos humanos" que el azar de las circunstancias políticas ponía a su disposición. De esta forma, por ejemplo, el Servicio Geológico Nacional fue promovido tras la llegada del insigne geólogo y paleontólogo español José Royo y Gómez que fue su fundador, siendo nombrado para ello Geólogo-Paleontólogo de este organismo en la misma fecha en que legalmente se creó. Idéntica circunstancia ha sido analizada con respecto a la Sección de Psicotecnia dentro de la Facultad de Medicina de la Universidad Nacional y Mercedes Rodrigo Bellido.

En el área de las Ciencias de la Actividad Física y el Deporte los responsables educativos colombianos, en 1942 procedieron a clausurar el Instituto Nacional de Educación Física existente y por decreto 166 del mismo año, se creó dentro de la Escuela Normal Superior la Sección de Educación Físi$c a$, cuya dirección se le otorgó a Manuel Usano Martín.

La Escuela Normal Superior había surgido tras la transformación liberal de la Facultad de Educación creada en el periodo presidencial de Enrique Olaya (1931-1934). Para organizar más fácilmente su estructura y funcionamiento, y controlar las medidas urgentes, así como para introducir los nuevos y renovadores objetivos, el siguiente gobierno de López trasladó su control directo al Ministerio de Educación Nacional. La Normal Superior se convirtió en un gran empeño liberal para iniciar una política de formación progresista de profesores para la educación secundaria, como motor e impulso en la reforma y modernización del país. En ella trabajaron como docentes importantes políticos liberales, e incluso varios ministros de educación, como Germán Arciniegas o Darío Echandía. Ellos personalmente aportaron su contribución conscientes de la carencia de profesorado cualificado. Echandía llegó a impartir sus clases simultáneamente a su desempeño del cargo de ministro.

Al Claustro de Profesores de la Escuela Normal Superior, el gobierno incorporó a Manuel Usano Martín. Igualmente habian sido y fueron siendo introducidos como profesores, a veces inmediatamente después de su llegada, un número importante de exiliados españoles: Francisco de Abrisqueta, Luis de Zulueta, Maria Rodrigo, Mercedes Rodrigo, Francisco Vera, José Prat García, José de Recaséns, Francisco Cirre, Pedro Urbano González de la Calle, Pablo Vila, José
Maria Ots Capdequí, Rafael Ureña, etc. Como resumen para este trabajo, apuntaremos que los exiliados españoles tuvieron un importante papel en la reforma educativa que los gobiernos liberales impulsaron en Colombia, en la enseñanza primaria, secundaria, universitaria, gran parte de ella adelantada desde aquella Norma ${ }^{14}$.

Al ser nombrado Manuel Usano director de la Sección de Educación Física que se creó en la Escuela Normal Superior se le solicitó que, dentro de su estructura ya de rango universitario, llevara a cabo la organización de un Instituto Nacional de Educación Física, dentro de aquella "gran facultad". Y, con los condicionantes que el gobierno regulaba directamente en ella, organizase los estudios correspondientes para el profesorado especialista, incorporando la organización básica con que contaba el anterior Instituto, en el que, como vimos, este español ya era parte fundamental.

Usano Martín cumplió con la labor de gestión y organización del Instituto Nacional de Educación Física que le fue encomendada, y que, transcurrido el tiempo, formó y tituló los primeros docentes universitarios de la especialidad en el país. Estructuró estos estudios superiores en cuatro años lectivos, en los que se impartieron, según se recoge en Socarrás $(1987,36)$, las materias: Física, Anatomía, Fisiología, Biometría, Higiene, Historia de la Educación Física, Gimnasia Sueca, Gimnasia con aparatos y rítmica, Danzas, Atletismo, Deportes, Natación, Juegos Pedagógicos, Defensa Personal, Traumatología, Metodología de la Enseñanza, Material Didáctico y Organización.

Manuel Usano se encargó de organizar y estructurar todos los planteamientos y todos los aspectos que fueron precisos para poner en marcha el citado Instituto Nacional de Educación Física dentro de la Normal Superior, tanto a nivel de organización académica, como de estructura, Plan de Estudios, etc., puesto que bajo su responsabilidad fue puesta la dirección de la nueva Sección en la que se encuadraba. Tras realizar las labores de planeación y organización del Instituto, desempeñó su Dirección desde su creación en 1942, hasta 1946. Su obra en este capítulo fue realmente pionera. Supuso elevar a rango de Facultad Universitaria los estudios de Profesorado de Educación Física, según se hizo después de muchos años en diversos paises de Europa y en España comenzando la década de los ochenta. 
Para la organización de aquel Instituto Superior de Educación Física, en la estructura universitaria de la Normal, Usano resultaba un profesional idóneo. Su trayectoria le había situado muy cercano a aquella misma experiencia llevada a cabo en la universidad española en 1933, ya citada. Por otro lado, su excepcional cualificación y su bagaje europeo le convertían en una oportunidad de privilegio para el país. Cabe por tanto destacar esta labor de $\mathrm{Ma-}$ nuel Usano en Colombia, como iniciativa pionera, promovida y factible únicamente sobre la base de sus exclusivas características profesionales, que tuvo una trascendencia definitiva en el posterior desarrollo de la Educación Física y el Deporte, al suponer la primera organización de estudios superiores universitarios en el país dentro del área.

El trabajo realizado por Manuel Usano le fue suponiendo un prestigio significativo. Su profesionalidad empezó a ser apreciada no sólo por su cualificación, sino también por su demostrada laboriosidad y su integridad moral. Discurrieron en su devenir profesional un importante número de puestos de responsabilidad. Entre 1941 y 1944 fue Presidente de la Liga de Atletismo del Departamento de Cundinamarca. En 1942 fue fundador del Club Atlético Escolar. Durante dos años trabajó como Director Técnico del citado club, período en el que se consiguieron importantes triunfos y en el que se erigió como campeón del Departamento.

En 1945 fue nombrado Director de Deportes de la Universidad Nacional, circunstancia que dio como resultado otra gran aportación pionera en Colombia de gran trascendencia para el Deporte colombiano. Desde aquella responsabilidad Manuel Usano repitió la misma labor de iniciar la organización del deporte universitario que había llevado a cabo en España en la Universidad de Valencia. Promovió la organización de todo tipo de equipos: atletismo, fútbol, baloncesto, etc. Con su iniciativa personal, creó la infraestructura y articulación de todas las competiciones de todos los deportes que los medios le permitieron, dentro de la universidad estatal. En esta fecha comenzó su trabajo como gestor y creador del equipo de Fútbol de la Universidad Nacional. Se encargó, igualmente, de la infraestructura y la gestión de las competiciones dentro del país entre los equipos de similares características que tenían una categoría semiprofesional. En las confrontaciones deportivas que llevó a cabo fueron invitados equipos de otros países iberoamericanos. Hemos podido consultar en su archivo personal una carta en la que se le comunica, como Director de Deportes de la Universidad Nacional, que había sido designado Delegado de la Universidad en la Comisión Nacional de Educación Física.

\subsection{Los V Juegos Centroamericanos y del Caribe}

Colombia estaba designada como país organizador de los $V$ Juegos Centroamericanos y del Caribe, que debian ser celebrados en 1946. Faltando menos de un año ${ }^{15}$ para su comienzo, y siendo Manuel Usano Director de Deportes de la Universidad Nacional, fue requerido para que asumiera la organización de los mismos. Su esposa Rosa Crespo nos decía que "fue llamado para ir a ver personalmente a Eduardo Santos"m6.

La aceptación de aquella gran responsabilidad suponía un delicado compromiso para Manuel Usano. Por una parte, se sentía obligado por su condición de exiliado acogido que debía agradecer el apoyo prestado. Por otra, implicaba un enorme reto al conllevar la organización de un trabajo que requería asumir una cantidad de tareas muy diversas y con mucha premura de tiempo. Debía encargarse de todo lo necesario para la celebración de un evento de trascendencia internacional. A pesar del poco tiempo que faltaba, aún quedaban por realizar múltiples trabajos de gran envergadura como: la construcción del alojamiento de los participantes, del estadio, la piscina olímpica, comedores, infraestructura del funcionamiento, de comidas, vestuario, etc.

Tras su aceptación fue nombrado Director Técnico de los V Juegos Centroamericanos y del Caribe. Para ello, puso la condición de poder elegir personalmente al equipo de profesionales que debian colaborar con él en la organización. Sobre ello recordaba su viuda Rosa Crespo Giner:

"Él conocía de la Universidad Nacional a Humberto Chica Pinzón que era arquitecto, y le nombró para que se encargara de la parte de construcción, los estadios, las habitaciones, los comedores... Después a otro muchacho que tenía allá una tienda de deportes, y que era también una persona muy responsable, le encargó de todo el tema relativo al material..." ${ }^{m 7}$.

El colosal esfuerzo de Usano Martín, permitió la exitosa celebración de aquellos eventos deportivos en Barranquilla, 
que fueron inaugurados el 8 de diciembre de 1946. Su familia incidió en el inmenso trabajo que ello le supuso, dedicando sus días y sus noches a ello, y por lo que apenas le veían. "Recuerdo la imagen de mi padre, muy delgado, que había perdido un montón de kilos"18.

En reconocimiento al importante servicio prestado a Colombia y como agradecimiento a su gran esfuerzo, le fue entregada, el 28 de diciembre de 1946, fecha de la clausura de los V Juegos Centroamericanos y del Caribe, la Medalla de Oro de la ciudad de Barranquilla ${ }^{19}$, detalle también corroborado por las fuentes gráficas de su álbum familiar. Sobre aquel día nos decía Rosa Crespo:

"El día de la clausura de los juegos, cuando todo el estadio estaba lleno de gente, le otorgaron la medalla por la dirección de los juegos, en nombre del pueblo de Barranquilla, porque les sacó del apuro, tenían una 'papeleta' impresionante, es que no habian hecho nada los primeros que estaban nombrados, no hicieron absolutamente nada, y por eso recurrieron a él"20.

La gran experiencia, laboriosidad y honradez de Manuel Usano salvaron de un importante compromiso internacional al gobierno colombiano. Reproducimos el párrafo más significativo de la carta de agradecimiento que le fue remitida por el Comité Organizador. Su contenido nos sitúa en la medida de la gran aportación que su trabajo significó, así como en sus características personales y profesionales:

"Tengo la profunda satisfacción de transmitir a usted el testimonio de reconocimiento de los importantes servicios prestados por usted al país, a la ciudad de Barranquilla y al Comité Organizador de los V Juegos Deportivos Centroamericanos y del Caribe, que esta entidad ha consignado en el Acta de su sesión de ayer: '... el Comité Organizador de dichos eventos deportivos deja en el Acta de esta sesión testimonio muy particular de su agradecimiento al señor Profesor Usano por los invaluables servicios prestados al País, a la ciudad de Barranquilla y al Comité, reconociendo de manera tan espontánea como sincera, como homenaje de justicia, que a los talentos y capacidades del Director Técnico, Profesor Usano, a sus profundos conocimientos deportivos, a su versación técnica, a sus grandes dotes organizativas, a su férrea voluntad y constancia, a su inquebrantable fe, a su fervoroso entusiasmo y a su reconocido don de gentes y a sus distinguidas cualidades de caballerosidad, se debe el éxito técnico alcanzado en los V Juegos Deportivos Centroamericanos y del Caribe, que tanto han contribuido a acrecentar el prestigio y las simpatías internacionales hacia Colombia, motivo por el cual el señor Profesor Manuel Usano se ha hecho altamente acreedor al reconocimiento y estimación del Gobierno y del pueblo colombiano "m21.

Toda su posterior estancia en Colombia siguió marcada por su vinculación a la Educación Física y el Deporte, respondiendo a las continuas demandas estatales de sus servicios relacionadas con eventos deportivos. Así, en 1946 fue nombrado, a pesar de su nacionalidad española, Miembro del Comité Olímpico Colombiano ${ }^{22}$. Estimamos que ello era consecuencia de que había demostrado que su nacionalidad no le impedía entregarse con toda generosidad y sin reticencias, en beneficio del país que le había acogido. En 1949 fue Delegado de Atletismo de Colombia en los II Juegos Bolivarianos de Lima (Perú); y en 1951 en los I Juegos Panamericanos de Buenos Aires (Argentina).

Manuel Usano dejó Colombia en el año 1953, al ser nombrado Director Médico y Supervisor de propaganda científica de los Laboratorios Pfizer de Nueva York, por lo cual se trasladó a los Estados Unidos en donde a partir de esa fecha discurrió su vida profesional y familiar.

\section{Conclusión}

Como consecuencia de los resultados de la Guerra Civil de 1936-39, un gran número de científicos, profesores, intelectuales, marcharon al exilio. Los impulsos modernizados que se habían iniciado en España promovidos por estos sectores quedaron abortados y proscritos en nuestro país, mientras que en otros lugares como Colombia, aquellos mismos españoles propiciaron la introducción de modernas áreas de conocimiento, nuevas especialidades y orientaciones renovadoras que situaron a los países que les acogieron a la cabeza de los adelantos técnicos, culturales y científicos. Colombia, en proceso acelerado de renovación e industrialización por parte de los gobiernos liberales seleccionó con gran adecuación a sus necesidades a los españoles republicanos acogidos. A través del ejemplo de la Psicología y de la Educación Física y el Deporte, abordado en este artículo se ofrece una muestra del gran avance que el trabajo de aquellos exiliados significó para el país. 
Recibido: 17 de febrero de 2008 Aceptado: 23 de abril de 2009

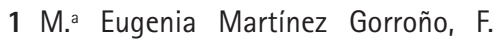
Vejarano y C. Hoyos, Españoles en Colombia siglo XX. Memoria y Sueños, Bogotá, Fundación Españoles en Colombia, Universidad Externado de Colombia, 2004

2 Miembro destacado de la izquierda liberal. Ministro de Educación en varios gobiernos liberales. Ocupó con López Pumarejo el cargo de "Designado" en varias ocasiones, que implicaba asumir todas las responsabilidades del Presidente en su ausencia.

3 Utilizamos terminología de la época, según se emplea en las fuentes.

4 A la sazón conformada por otro original grupo familiar: Ignacio y José Prat García (Diputado y Subsecretario de la Presidencia del Gobierno durante el periodo correspondiente a Juan Negrín. Tras la democracia, Senador y Presidente del Ateneo de Madrid), su compañera Ramona González, con su madre y su hijo (que fue nuestra excepcional fuente oral), así como el padre de los Prat, D. Ignacio, maestro y músico.

5 Según Velásquez Toro (1989), el 53\% eran analfabetas, pero personalmente nos parece una cifra demasiado poco elevada para la fecha y las circunstancias en las que se desenvolvía el país.

6 Desconocemos la fecha de creación de aquel Instituto García Madrid, cuya existencia sólo hemos podido documentar a partir del testimonio de varias fuentes orales, jóvenes exiliados que colaboraron y participaron como ayudantes en aquel impulso pionero, como Ascensión Madariaga, Carmen y Virginia Mayoral Herrero o el ya citado Ramón González.

8 Experiencia iniciada en 1828 cuando Thomas Arnold obtuvo la dirección de la Public School de Rugby y que por su éxito se extendió por todo el Reino Unido, configurando la forma de Educación Física británica que influyó decisivamente en Pierre de Coubertin.

9 Pérez Galán, M., "La enseñanza en la Segunda República", Cuardernos para el Diálogo, Madrid, 1977, 151-153.

10 Aunque ciertos datos de Fernández Nares, nos dicen que aquella vía legal, tuvo cierta vigencia y se expidieron, en aquel centro entre 1932 y 1979, 692 títulos de profesor de E.F.

11 De entrevista con Rosa Crespo Giner, celebrada en Madrid el 9 de octubre de 1991.

12 Cundinamarca es el Departamento cuya capital es Bogotá.

13 Fisiología, Kinesioterapia, Biométrica y Atletismo, además de ser nombrado Jefe de los Laboratorios de Investigación y Prácticas.

14 Para ampliar este aspecto puede consultarse Migraciones \& Exilios n. ${ }^{\circ} 4$ Citada en la bibliografía.

15 Las fuentes orales han mencionado entre seis y ocho meses. Una carta de su archivo personal remitida por $\mathrm{Co}_{-}$ mité Organizador y dirigida a Manue Usano, le comunica su nombramiento como Director Técnico de los mismos con fecha 12 de agosto de 1946.

16 De entrevista con Rosa Crespo Giner celebrada en Madrid el 9 de octubre de 1991.

17 De entrevista mantenida con Maricel Usano Crespo en Madrid en noviembre de 1991.

18 De entrevistas con Maricel Usano Crespo. Madrid 9 de octubre y 18 de noviembre de 1991.

7 Sus datos más completos y su análisis puede consultarse en Martínez Gorroño, 1999, citada en bibliografía.
19 Múltiples fotografias de su archivo familiar documentan el acto de imposición de la Medalla. 
20 De entrevista con Rosa Crespo Giner celebrada en Madrid el 9 de octubre de 1991.

21 Carta remita por Rafael Gerlain y Villate, Presidente del Comité Organizador, a Manuel Usano Martín, fechada el 8 de marzo de 1947.

22 Según currículum de su archivo personal.

\section{BIBLIOGRAFÍA Y FUENTES}

Ardila, Rubén (1973): La Psicología en Colombia. Desarrollo histórico, México, Trillas.

Ardila, Rubén (1988): "Mercedes Rodrigo (1891-1982)", Revista latinoamericana de Psicología, 20,3, 429-434.

Carpintero, H. (1994): Historia de la Psicología en España, Madrid, Eudema.

Arizmendi Posada, Ignacio (1989): Presidentes de Colombia, Bogotá, Planeta.

Capel, R. (1982): El trabajo y la educación de la mujer en España. 1900-1930, Ministerio de Cultura.

Contecha Carrillo, Luis Felipe (1999): "La Educación Física y el Deporte en Colombia. Una Historia", Lecturas: Educación Física y Deportes, Revista Digital, año 4, n.o 17, Buenos Aires, diciembre. http://www.sportquest. com/revista/.revista digital.

García Nieto, Carmen (1982): Guerra civil española, 1936-1939, Barcelona, Salvat.

Giral, Francisco (1994): Ciencia Española en el Exilio (1939-1989), Madrid, Anthropos.

Herrero González, Fania (2000): Mercedes Rodrigo: Una pionera de la psicología aplicada en España y Colombia, Facultad de Filosogía, Universidad Complutense de Madrid.

Herrero González, Fania (2005): "Mercedes Rodrigo Bellido (1891-1982), la primera psicóloga española. Aproxima- ción a su vida y a su obra", Simposio "Historia de la Psicología Aplicada en España", Baeza (Jaén).

Jaramillo Uribe, Jaime (1989): "La educación en los gobiernos liberales 19301946", en Álvaro Tirado Mejía (dir.): Nueva Historia de Colombia, t. IV, Bogotá, Planeta, 87-110.

López Serra, Francisco (1998): Historia de la Educación Física de 1876 a 1898. La Institución Libre de Enseñanza, Madrid, Gymnos.

Magdalena, Ángel María (1992): Los Pioneros españoles del olimpismo moderno, Asturias, Servicio de Publicaciones del Principado de Asturias.

Marín Eced, T. (1990): La renovación pedagógica en España (1907-1936). Los pensionados en pedagogía por la Junta para Ampliación de Estudios, Madrid, CSIC.

Martínez Gorroño, M. ${ }^{a}$ Eugenia (1990): "Fuentes orales para una aproximación al exilio femenino en Colombia", Espacio, Tiempo y Forma, V, 3, 85-104.

Martínez Gorroño, M. ${ }^{a}$ Eugenia (1992): Españoles en Colombia. Médicos y Odontólogos exiliados a consecuencia de la guerra civil en España, Madrid, Fundación Españoles en el Mundo.

Martínez Gorroño, M. ${ }^{a}$ Eugenia (1996): Vasco-navarros en Colombia: una aportación del exilio consecuencia de la guerra civil de 1936-1939, Madrid, Fundación Españoles en el Mundo.

Martínez Gorroño, M. ${ }^{a}$ Eugenia (1999): Españolas en Colombia. La huella cultural de las mujeres exiliadas tras la guerra civil, Madrid, Fundación Españoles en el Mundo.

Martínez Gorroño, M. ${ }^{a}$ Eugenia (2003): "La educación en la Colombia liberal de los años 30 y 40: la trascendente contribución del exilio español consecuencia de la guerra civil de 1936-
1939", en Migraciones \& Exilios, n. ${ }^{\circ}$, Madrid, AEMIC, 9-30.

Martínez Gorroño, M. ${ }^{a}$ Eugenia; Vejarano, Fernando y Hoyos, Carlos (2004): Españoles en Colombia siglo XX. Memoria y Sueños, Bogotá, Fundación Españoles en Colombia, Universidad Externado de Colombia, 2004.

Martínez Gorroño, M. ${ }^{a}$ Eugenia (2008): en Pla Brugat (coords.) Pan, Trabajo y Hogar, México D.F., Instituto de Antropología.

Roca de Torres, I. (1993): "La A.P.P.R.: Una perspectiva histórica", Revista Puertorriqueña de Psicología, vol. 9, pp. 109-127.

Rodrigo Bellido, Mercedes (1933): "Algunos problemas de Orientación profesional", Medicina del trabajo e Higiene Industrial, 17 y 18; 93-160.

Rodrigo Bellido, Mercedes (1949): "El Instituto de Psicología Aplicada, fundación y plan de estudios", Universidad Nacional de Colombia, Bogotá.

Velásquez Toro, Magdalena (1989): "Condición jurídica y social de la mujer", Nueva Historia de Colombia, IV, Bogotá, Planeta, 9-60.

Villar Gaviria, Álvaro (1965): "Desarrollo de la Psicología en Colombia. Aporte para el estudio de su historia", Revista de Psicología, X, Bogotá, 7-26.

\section{Fuentes orales}

En este trabajo ha sido tomada información obtenida en entrevistas mantenidas con: Ramón González García (exiliado de 2. generación), Madrid, octubre 1998. José Prat Garcia (exiliado de 1. ${ }^{a}$ generación), Madrid, octubre 1992. Ascensión Madariaga (exiliada de $1 .^{\text {a }}$ generación), Bogotá 1990. Rosa Crespo Giner (exiliada 1. ${ }^{a}$ generación), Madrid, octubre 1991. M. ${ }^{\mathrm{a}}$ Cel Usano Crespo (exiliada 2. ${ }^{\text {a }}$ generación), Madrid, noviembre 1991. 